\title{
Population Structure of Dogwood Anthracnose Fungus
}

\author{
Ning Zhang and Meredith Blackwell
}

Department of Biological Sciences, Louisiana State University, Baton Rouge 70803.

Accepted for publication 15 July 2002.

ABSTRACT

\begin{abstract}
Zhang, N., and Blackwell, M. 2002. Population structure of dogwood anthracnose fungus. Phytopathology 92:1276-1283.

Dogwood anthracnose, caused by Discula destructiva, affects several native dogwood species in North America, especially flowering dogwood in the east and Pacific dogwood in the west. The fungus behaves as a recently introduced plant pathogen under episodic selection. Two distinct disjunct groups of fungal isolates corresponding to eastern and western groups were detected by amplified fragment length polymorphisms and sequences of the intergenic spacer (IGS) of the nuclear ribosomal DNA, translation elongation factor- $1 \alpha$, and $\beta$-tubulin genes. Of 20 genotypes identified among 72 isolates, 17 genotypes were from the eastern United
\end{abstract}

States $(n=50)$, but only three were present among the western isolates $(n=22)$, indicating that the eastern population may be more diverse. Most eastern and western isolates belonged to a few widespread clones, and the genetic variability of this apparently asexual fungus was remarkably low compared with that of many other asexual fungi. We conclude that $D$. destructiva is still under intense selection pressure and that episodic selection may still be in effect. The New York City area, a possible epidemic center in the east, had relatively higher genetic variability than samples from other areas.

Additional keywords: Cornus, Diaporthales, genotypic diversity.
Brasier $(3,4)$ described the effects of episodic selection on fungal populations, a phenomenon in which a sudden environmental disturbance is likely to lead to a significant alteration in the population structure of certain fungal species. Such a disturbance, perhaps a geographic transposition, association with a new host or vector, hybridization, or climate change, might result in the emergence of a highly virulent or fit clone from an originally heterogeneous sexual population. Under these conditions, intense selection pressure eliminates or suppresses less fit genotypes. If routine selection is reinstated, the population reverts to an outcrossing, highly heterogeneous population. Continued episodic selection, however, may result in speciation. This model was based on the study of emerging fungal pathogens such as Ophiostoma novo-ulmi, the causal agent of a new wave of Dutch elm disease $(3,4)$. The model also is likely to provide an explanation of the emergence of dogwood anthracnose fungus and predict its evolution.

Dogwood anthracnose, caused by Discula destructiva, is a disease of several dogwood species native to North America, especially flowering and Pacific dogwoods (Cornus florida and $C$. nuttallii) (13). Its symptoms include bract necrosis, leaf spot, leaf blight, twig dieback, and trunk canker. The spores probably are dispersed by splashing rain and insects. Isolation of the fungus from fruit and seed of infected dogwood trees indicates that birds might contribute to long-distance dissemination of $D$. destructiva (11). The fungus survives the winter in the host and leaf symptoms generally begin to occur in the early spring of the next year. Infected trees may be killed in years when environmental conditions are favorable to the fungus $(10,18)$. In culture, $D$. destructiva reproduces by production of asexual spores in 1 to 4 weeks or longer depending on the type of medium. Sporulation is enhanced by adding leaves of plants such as dogwood and oak to the medium and by using a light/dark cycle. Optimal growth and sporulation was found at 21 to $24^{\circ} \mathrm{C}$ (11).

Corresponding author: M. Blackwell; E-mail address: mblackwell@1su.edu

Publication no. P-2002-0930-01R

(C) 2002 The American Phytopathological Society
The disease was found only in North America but a thorough search of dogwoods on other continents has not been made. The first report of the disease was on Pacific dogwood in the northwestern United States in the 1970s (5). It also appeared suddenly on flowering dogwood in southeastern New York and southwestern Connecticut at almost the same time (24). Since then, the disease has spread rapidly through native dogwood populations and has caused dramatic devastation. Since that time, infections have been confirmed from British Columbia, Washington, Oregon, Idaho, and California in the western part of North America. In the east, the disease has been reported from New York, Connecticut, Massachusetts, Vermont, New Jersey, Pennsylvania, Delaware, Maryland, Virginia, West Virginia, North Carolina, South Carolina, Tennessee, Kentucky, Indiana, Michigan, Ohio, New Hampshire, Rhode Island, Missouri, Kansas, and as far south as Georgia and Alabama $(11,17)$.

The fungus reproduces by asexual spores (mitospores or conidia). A sexual state is unknown. Redlin (28) examined over a hundred collections from various regions in eastern and western North America. He reported that they were similar in morphology and described the pathogen as a new species of asexual fungus, $D$. destructiva. Molecular phylogenetic analyses placed it in the Diaporthales, an order of ascomycetes including a number of plant pathogens such as the chestnut blight fungus (43).

The origin of $D$. destructiva in North America remains a mystery, though some evidence indicates that it may have been introduced rather recently. Morphology and DNA amplification fingerprinting (DAF) indicated that $D$. destructiva isolates were highly homogeneous regardless of their collection site or host, suggesting that this fungus might be a single recent introduction to North America (37). However, the banding profiles of double-stranded RNA (dsRNA), a virus-like genetic element frequently found in the cytoplasm of many fungi, were different between eastern and western isolates $(32,41)$. In addition, the generation of arbitrary signatures from amplification profiles (ASAP) distinguished subpopulations from northeastern, southeastern, and western North America (6). These studies suggested that the eastern and western D. destructiva populations might have had different origins, although the overall genetic variability was relatively low compared with that in other species (7). 
D. destructiva populations' sudden emergence, rapid spread in native North American dogwoods, and low genetic variability point to episodic selection as a potentially important force. There has been a suggestion (S. Anagnostakis, personal communication, 1997) that the disease now is less virulent than that of 2 decades ago in northeastern North America. This observation may indicate that selection pressures have eased and the fungal populations are now undergoing routine selection that might be detected by increased genetic variability among North American populations. In order to test this hypothesis, we included more recent collections (1999 to 2000) to compare genetic variability with the older isolates (1989 to 1990). We also wanted to obtain data to determine if southeastern New York was the center of the early epidemic by using the criterion of high genetic variability in comparison to that of the frontal sites. Although Caetoano-Anollés and colleagues (6) had distinguished subpopulation structure within D. destructiva, they arbitrarily combined the mycelia of isolates from adjacent locations (e.g., Massachusetts, Pennsylvania, and Maryland). Therefore, genetic variability within subpopulations could not be accessed from their study.

The main tool we used in this study was detection of amplified fragment length polymorphisms (AFLP), a highly efficient and reproducible genotyping technique that has been applied to a number of organisms, such as bacteria (26), plants (38), fungi (36), and animals (30), including humans (25). In comparison to other commonly used genotyping tools such as random amplified polymorphic DNA and restriction fragment length polymorphism markers, many researchers have found that AFLP markers are more powerful in distinguishing highly homogeneous populations $(16,34,42)$. In addition to AFLP markers, sequencing of several protein-coding and noncoding genes and virulence tests also were performed in order to address the following questions. (i) What is the population structure of $D$. destructiva? (ii) Where is the epidemic center of dogwood anthracnose? (iii) Is virulence correlated with the population structure? (iv) Has routine selection been reestablished in more recent $D$. destructiva populations or has speciation occurred?

\section{MATERIALS AND METHODS}

Fungal isolates. Seventy-two isolates of D. destructiva were included in the study. The isolates were collected as available, not randomly, from different host plants or in a few cases, from the same host if different symptoms were present. From the west, we used 22 samples: two collected from Oregon in 2000, the others from Washington more than a decade ago. Fifty eastern samples were analyzed, including one North Carolina sample and 14 Maryland samples collected in 1999 and 2000; others were collected during 1989 to 1991 from nine eastern states. In the 35 older eastern samples, 15 were from Maryland, New Jersey, and Pennsylvania, the area near New York City, and are referred to as the eastern central group (Fig. 1, isolates within the circle). The other 20 make up the eastern frontal group, which were from Massachusetts, Ohio, North Carolina, and as far south as Georgia. Both the 1990 and 1999 Catoctin Mountain Park (CMNP), Maryland, collections were from approximately the same $10-\mathrm{km}^{2}$ area. Table 1 and Figure 1 provide more details. Fungal cultures were preserved on potato dextrose agar at $4^{\circ} \mathrm{C}$ and transferred to fresh medium every 4 to 5 years.

DNA extractions, polymerase chain reaction, cloning, and sequencing. Cultures were grown in $2 \%$ malt extract broth and harvested after 1 week. Mycelia were frozen in liquid nitrogen and ground to a fine powder with a mortar and pestle. Total nucleic acids were extracted by a Dneasy Plant Mini Kit (Qiagen, Valencia, CA). Six to twelve isolates from several different localities were selected for sequencing of the six following DNA regions. Partial nuclear encoded small subunit rDNA genes (SSU rDNA) and large subunit rDNA genes (LSU rDNA) were amplified with primers NS1 and NS6 (40) and ITS3 and LR3 (29), respectively. The internal transcribed spacer (ITS) region was amplified with primers ITS5 and ITS4 (40). Purified polymerase chain reaction (PCR) products were used for cycle sequencing directly with the amplification primers. Translation elongation factor 1 alpha (EF$1 \alpha$ ), chitin synthase 1 (CHS-1), and $\beta$-tubulin genes were amplified and sequenced with the primers EF1-728F/EF1-986R, CHS-79F/ CHS-354R (8), and $\mathrm{Bt} 2 \mathrm{a} / \mathrm{Bt} 2 \mathrm{~b}$ (15), respectively. Several primers (DIGS1: GTAAGTCCGCTTTTCCCATGTG, DIGS2: CTGCTAGGCATTAGACTACG, DIGS6: CATTTGGCTCGTGAGTCGTG, DIGS8: GCACGCCAGTTTGTGTATGAG, DIGS10: GCTGTAATCCAGCGTTGTG, and their reverse) were designed for PCR and sequencing of the intergenic spacer (IGS). The IGS PCR products were cloned with a cloning kit for sequencing (TOPO TA; Invitrogen, Carlsbad, CA). In the cycle sequencing reactions, M13 forward and reverse primers provided with the cloning kit were used to obtain the inserted DNA sequences. Sequencing was performed on an automated sequencer (ABI PRISM 377; PerkinElmer Applied Biosystems, Foster City, CA).

AFLP techniques. We used an AFLP plant mapping kit for regular genome and microbial fingerprinting kit (Perkin-Elmer Applied Biosystems). Total genomic DNA was digested with EcoRI and MseI and the restriction fragments were then ligated to adapters, which function as annealing sites or core designed for specific primers in subsequent PCR. By changing the number and sequence of the nucleotides adjacent to the core, we could selectively amplify restriction fragments that matched the primer sequences. Genomic variability was revealed by comparing the banding profiles. The amplification products were detected by an automated sequencer (ABI PRISM 377). The size of the products was determined by using GeneScan 3.1 fragment analysis software (Perkin-Elmer Applied Biosystems). The primer pair EcoRI$\mathrm{A} /$ MseI-C was used in the preselective amplification reactions. Fifty-seven pairs of selective primers were screened and two pairs (EcoRI-AC/MseI-C and EcoRI-AA/MseI-0) that showed the greatest number of polymorphisms were chosen for analysis of all isolates. The unweighted pair group method with arithmetic averages clustering was performed by the NTSYS-pc 1.80 software (written by F. J. Rohlf, Exeter Software, Setauket, NY) using the Dice coefficient (also known as Nei and Li's coefficient of similarity [22]), which is equal to twice the number of common bands divided by the number of all bands in the two profiles. Genotypic diversity, the probability that two randomly chosen genotypes are different in the sample (21), was calculated by Arlequin 1.1 (written by S. Schneider, J. M. Kueffer, D. Roessli, and L. Excoffier, University of Geneva, Switzerland) as the indicator of genetic variability. Fisher's $\alpha$, another diversity index that is relatively unbiased by sample size (20), was calculated with EstimateS $6.0 \mathrm{~b} 1$ (written by R. K. Colwell, University of Connecticut).

Virulence tests. Cultures were set up as described by Redlin (28). Healthy young leaves were collected from a $D$. destructivafree flowering dogwood tree on the Louisiana State University campus (Baton Rouge, East Baton Rouge Parish). The leaves were cut into leaf disks with a 22-mm-diameter cork borer, surface disinfested with a $1 \%$ sodium hypochlorite solution, rinsed with sterile distilled water, blotted dry, and set into wells on water agar, adaxial side uppermost. Each leaf disk was burned in the middle to cause a wound of 3 to $4 \mathrm{~mm}$ in diameter. An agar plug $(4 \times 4 \mathrm{~mm})$, cut from the margin of a 1-week-old culture, was transferred to the wound. The plates containing water agar and inoculated leaf disks were placed in an incubator at $23^{\circ} \mathrm{C}$ with a 12-h light/dark cycle. There were three replicates for each isolate. Plates were placed randomly in the incubator. After 3 weeks, the percentage of leaf area that contained conidiomata of $D$. destructiva was recorded. Replicates of the same isolates were inoculated and recorded at the same time. Statistical analyses ( $t$ tests) were performed using SAS 8.01 (SAS Institute, Cary, NC). Virulence of 
11 randomly selected $D$. destructiva isolates also were tested at 28 and $32^{\circ} \mathrm{C}$. Data were recorded in the same way as described previously.

Vegetative compatibility tests. The 72 isolates were paired in all possible combinations on potato dextrose agar plates with food coloring (31) and cultured under the same conditions as for the virulence tests. Cultures were observed every month for a year.

\section{RESULTS}

AFLP. Primer pair EcoRI-AC/MseI-C detected 50 bands in the size range of 40 to $500 \mathrm{bp}$, of which 12 were polymorphic. EcoRIAA/MseI-0 amplified 67 fragments, only three of which were polymorphic. The other 55 primer pairs either produced very few polymorphic sites or had poor amplification. Twenty genotypes were identified based on both primer pair data sets. The phenogram (Fig. 2) produced from the similarity matrix separated the disjunct western and eastern isolates, with western isolates (WEST) forming a cluster and eastern ones (EAST) grouped in another cluster, except for a Maryland collection (MD233), which was placed outside both of the major groups. The WEST cluster had only three genotypes (Q, R, and S) (Fig. 2 and Table 1), whereas the EAST cluster (MD233 excluded) had 16 genotypes. Genotypes B, C, F, Q, and R were dominant and widespread, and other genotypes had only one or a few members. The genotypic diversity (21) of isolates in the WEST cluster (0.45) was much lower than that of the EAST cluster (0.82). In the east, the 1989 to 1990 isolates from the hypothesized epidemic central area (Maryland, New Jersey, and Pennsylvania) had much higher genotypic diversity than those from the epidemic frontal area (Georgia, North Carolina, Virginia, West Virginia, and Massachusetts). For both early and late collections, there were approximately 10 genotypes identified from the central area. However, with the exception of one $\mathrm{C}$ isolate in Massachusetts, only the $\mathrm{B}$ and $\mathrm{F}$ genotypes were identified in the eastern frontal group. The CMNP population had no significant change in genotypic diversity between the years 1990 and 1999 (Table 2). The comparison of Fisher's $\alpha$ showed the same patterns as shown by genotypic diversity estimates.

Virulence. The WEST and EAST clusters (Fig. 2) did not differ significantly in their virulence, nor did the eastern central and frontal groups. However, significantly higher virulence was shown in the CMNP (Maryland) collections of 1999 compared with the earlier collections of 1990 from the same area (Table 2). The 11 samples cultured at 28 and $32^{\circ} \mathrm{C}$ showed less than $0.2 \%$ virulence, whereas at $23^{\circ} \mathrm{C}$, virulence of the same isolates ranged from 9 to $95 \%$ (data not shown).

Vegetative compatibility tests. In the vegetative compatibility tests, no obvious barrage zones or antibiosis reactions were observed in any of the over 2,000 pairings.

Gene sequences. No sequence variation was detected from the SSU (1,005 bp, GenBank Accession Nos. AF277126 and AF429717 to AF429719), LSU (569 bp, GenBank Accession Nos. AF277136 and AF429721 to AF429723), ITS (550 bp, GenBank Accession Nos. AF429741 to AF429748), or CHS-1 (261 bp, GenBank Accession Nos. AF429724 to AF429729) regions of the selected isolates. Between the WEST and EAST clusters, a fixed T/C transition was found in the $\beta$-tubulin sequences ( $500 \mathrm{bp}$, GenBank Accession Nos. AF429736 to AF429740) and a fixed G/A transition in EF-1 $\alpha$ sequences (352 bp, GenBank Accession Nos. AF429730 to AF429735), whereas no sequence variation was detected within either cluster. Sequences of the isolate MD233 were the same as those of all EAST cluster isolates. The IGS region of $D$. destructiva was approximately $4.2 \mathrm{~kb}$ in eastern isolates and $3.6 \mathrm{~kb}$ in western isolates. Approximately $600 \mathrm{bp}$ at the $5^{\prime}$ end (GenBank Accession Nos. AF429749 to AF429755) and $2 \mathrm{~kb}$ at the $3^{\prime}$ end of the IGS sequences (GenBank Accession Nos.

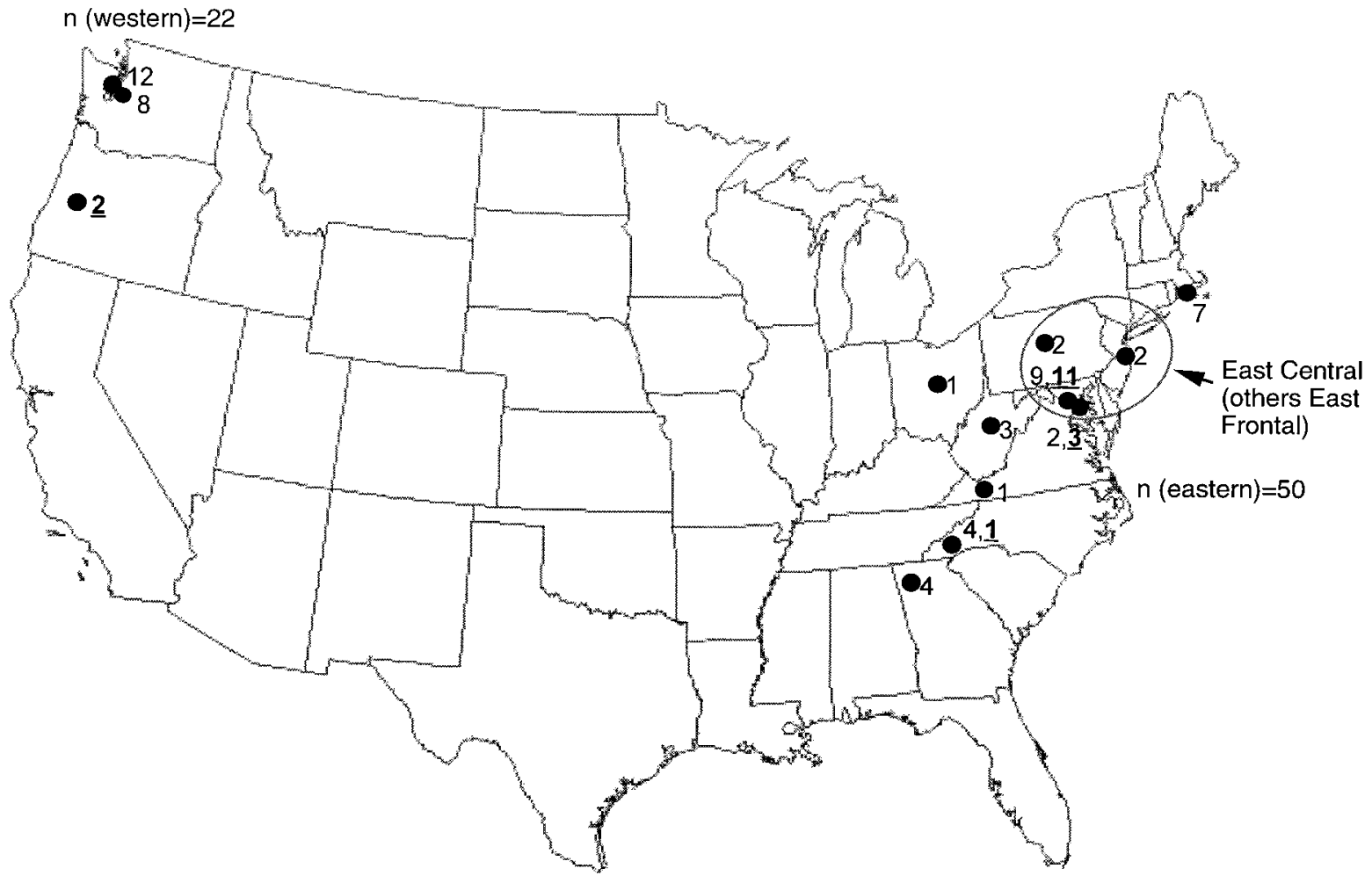

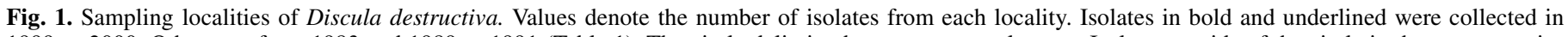

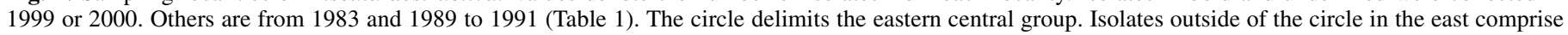
the eastern frontal group. 
TABLE 1. Discula destructiva isolates used in this study and amplified fragment length polymorphism and virulence test results

\begin{tabular}{|c|c|c|c|c|c|c|}
\hline Isolate & Host & Location & Genotype & Year of collection & Source ${ }^{a}$ & Virulence $^{b}$ \\
\hline WA206 & Cornus nuttallii & Seattle, WA & Q & 1990 & SCR & $31.0 \pm 11.6$ \\
\hline WA207 & C. nuttallii & Seattle, WA & Q & 1990 & SCR & $6.7 \pm 3.3$ \\
\hline WA210 & C. nuttallii & Seattle, WA & $\mathrm{R}$ & 1990 & SCR & $13.3 \pm 4.4$ \\
\hline WA212 & C. nuttallii & Seattle, WA & Q & 1990 & SCR & $20.3 \pm 15.1$ \\
\hline WA220 & C. nuttallii & Seattle, WA & Q & 1990 & SCR & $0.3 \pm 0.3$ \\
\hline WA221 & C. nuttallii & Seattle, WA & $\mathrm{Q}$ & 1990 & SCR & $36.7 \pm 21.9$ \\
\hline WA222 & C. nuttallii & Seattle, WA & Q & 1990 & SCR & $94.7 \pm 4.8$ \\
\hline WA1653 & C. nuttallii & Seattle, WA & Q & 1983 & WHT & $41.7 \pm 24.2$ \\
\hline WAP1 & C. nuttallii & Poulsbo, WA & Q & 1990 & SCR & $7.0 \pm 4.2$ \\
\hline WAP2 & C. nuttallii & Poulsbo, WA & $\mathrm{R}$ & 1990 & SCR & $21.7 \pm 14.2$ \\
\hline WAP3 & C. nuttallii & Poulsbo, WA & Q & 1990 & SCR & $11.7 \pm 4.4$ \\
\hline WAP4 & C. nuttallii & Poulsbo, WA & Q & 1990 & SCR & $48.3 \pm 25.9$ \\
\hline WAP5 & C. nuttallii & Poulsbo, WA & $\mathrm{R}$ & 1990 & SCR & $73.7 \pm 24.2$ \\
\hline WAP6 & C. nuttallii & Poulsbo, WA & $\mathrm{S}$ & 1990 & SCR & $8.3 \pm 0$ \\
\hline WAP11 & C. nuttallii & Poulsbo, WA & $\mathrm{R}$ & 1989 & SCR & $12.7 \pm 10.3$ \\
\hline WAP31 & C. nuttallii & Poulsbo, WA & Q & 1989 & SCR & $91.7 \pm 8.3$ \\
\hline WAP33 & C. nuttallii & Poulsbo, WA & $\mathrm{S}$ & 1989 & SCR & $35.0 \pm 15.0$ \\
\hline WAP37 & C. nuttallii & Poulsbo, WA & Q & 1989 & SCR & $68.3 \pm 29.2$ \\
\hline WAP40 & C. nuttallii & Poulsbo, WA & Q & 1989 & SCR & $83.0 \pm 16.5$ \\
\hline WAP272 & C. nuttallii & Poulsbo, WA & $\mathrm{Q}$ & 1990 & SCR & $5.3 \pm 2.6$ \\
\hline OR1 & C. nuttallii & Lane County, OR & Q & 2000 & $\mathrm{GC}$ & $77.3 \pm 22.2$ \\
\hline OR2 & C. nuttallii & Eugene, OR & Q & 2000 & $\mathrm{GC}$ & $44.7 \pm 28.1$ \\
\hline MAK1 & C. kousa & Vineyard Haven, MA & $\mathrm{B}$ & 1989 & SCR & $7.0 \pm 3.0$ \\
\hline MAK2 & C. kousa & Vineyard Haven, MA & $\mathrm{B}$ & 1989 & SCR & $1.7 \pm 1.7$ \\
\hline MAK3 & C. kousa & Vineyard Haven, MA & $\mathrm{B}$ & 1989 & SCR & $50.3 \pm 25.8$ \\
\hline MAK5 & C. kousa & Vineyard Haven, MA & $\mathrm{B}$ & 1989 & SCR & $6.7 \pm 3.3$ \\
\hline MAF2 & C. florida & Vineyard Haven, MA & $\mathrm{F}$ & 1989 & SCR & $0 \pm 0$ \\
\hline MAF3 & C. florida & Vineyard Haven, MA & $\mathrm{F}$ & 1989 & SCR & $40.0 \pm 15.3$ \\
\hline MAF5 & C. florida & Vineyard Haven, MA & $\mathrm{C}$ & 1989 & SCR & $26.7 \pm 24.2$ \\
\hline NJ307 & C. florida & Morristown, NJ & $\mathrm{C}$ & 1990 & SCR & $66.3 \pm 30.7$ \\
\hline NJ308 & C. florida & Morristown, NJ & $\mathrm{F}$ & 1990 & SCR & $98.3 \pm 1.7$ \\
\hline PA1 & C. florida & Philadelphia County, PA & $\mathrm{J}$ & 1989 & SCR & $5.3 \pm 2.6$ \\
\hline PA5 & C. florida & Philadelphia County, PA & $\mathrm{K}$ & 1989 & SCR & $89.0 \pm 11.0$ \\
\hline MD203 & C. florida & Green Belt Park, MD & $\mathrm{G}$ & 1990 & SCR & $5.0 \pm 0$ \\
\hline MD205 & C. florida & Green Belt, MD & $\mathrm{C}$ & 1990 & SCR & $45.0 \pm 28.4$ \\
\hline MD231 & C. florida & Catoctin Mountain Park (CMNP), MD & $\mathrm{H}$ & 1990 & SCR & $17.7 \pm 8.2$ \\
\hline MD233 & C. florida & $\mathrm{CMNP}, \mathrm{MD}$ & $\mathrm{T}$ & 1990 & SCR & $5.0 \pm 0$ \\
\hline MD234 & C. florida & CMNP, MD & $\mathrm{O}$ & 1990 & SCR & $17.7 \pm 9.6$ \\
\hline MD235 & C. florida & CMNP, MD & $\mathrm{N}$ & 1990 & SCR & $58.3 \pm 8.3$ \\
\hline MD237 & C. florida & CMNP, MD & $\mathrm{C}$ & 1990 & SCR & $25.0 \pm 7.6$ \\
\hline MD240 & C. florida & CMNP, MD & $\mathrm{B}$ & 1990 & SCR & $2.3 \pm 1.3$ \\
\hline MD247 & C. florida & CMNP, MD & $\mathrm{P}$ & 1990 & SCR & $8.7 \pm 5.8$ \\
\hline MD254 & C. florida & CMNP, MD & $\mathrm{C}$ & 1990 & SCR & $60.7 \pm 5.3$ \\
\hline MD304 & C. florida & CMNP, MD & $\mathrm{D}$ & 1990 & SCR & $17.0 \pm 14.0$ \\
\hline MDno1 & C. florida & Beltsville, MD & $\mathrm{F}$ & 1999 & NZ/MB/GS & $41.3 \pm 29.7$ \\
\hline MDno12 & C. florida & CMNP, MD & B & 1999 & NZ/MB/GS & $51.7 \pm 23.3$ \\
\hline MDno22 & C. florida & Beltsville, MD & $\mathrm{C}$ & 1999 & NZ/MB/GS & $83.3 \pm 16.7$ \\
\hline MDno26 & C. florida & Green Belt, MD & $\mathrm{C}$ & 1999 & NZ/MB/GS & $55.0 \pm 22.5$ \\
\hline MDRR1 & C. florida & CMNP, MD & A & 1999 & RR & $98.0 \pm 1.5$ \\
\hline MDRR2 & C. florida & CMNP, MD & B & 1999 & RR & $59.3 \pm 18.5$ \\
\hline MDRR3 & C. florida & CMNP, MD & $\mathrm{L}$ & 1999 & RR & $44.7 \pm 22.3$ \\
\hline MDRR4 & C. florida & CMNP, MD & M & 1999 & RR & $83.6 \pm 9.0$ \\
\hline MDRR5 & C. florida & CMNP, MD & $\mathrm{E}$ & 1999 & RR & $10.0 \pm 5.0$ \\
\hline MDRR6 & C. florida & CMNP, MD & $\mathrm{F}$ & 1999 & RR & $78.3 \pm 11.7$ \\
\hline MDRR7 & C. florida & CMNP, MD & $\mathrm{H}$ & 1999 & RR & $24.3 \pm 4.3$ \\
\hline MDRR8 & C. florida & CMNP, MD & $\mathrm{B}$ & 1999 & RR & $99.7 \pm 0.3$ \\
\hline MDRR9 & C. florida & CMNP, MD & I & 1999 & RR & $0 \pm 0$ \\
\hline MDRR10 & C. florida & CMNP, MD & $\mathrm{F}$ & 1999 & RR & $22.0 \pm 11.0$ \\
\hline WV264 & C. florida & Gilmer County, WV & $\mathrm{F}$ & 1990 & SCR & $86.3 \pm 13.2$ \\
\hline WV266 & C. florida & Upshur County, WV & $\mathrm{F}$ & 1990 & SCR & $52.3 \pm 26.6$ \\
\hline WV271 & C. florida & Barbour County, WV & $\mathrm{F}$ & 1990 & SCR & $8.3 \pm 6.0$ \\
\hline VA61 & C. florida & Floyd County, VA & $\mathrm{B}$ & 1989 & SCR & $55.0 \pm 16.1$ \\
\hline OH327 & C. florida & Franklin County, $\mathrm{OH}$ & $\mathrm{F}$ & 1991 & SCR & $16.7 \pm 16.7$ \\
\hline NC84 & C. florida & Macon County, NC & $\mathrm{B}$ & 1989 & SCR & $8.3 \pm 1.7$ \\
\hline NC85 & C. florida & Macon County, NC & B & 1989 & SCR & $17.0 \pm 16.5$ \\
\hline NC86 & C. florida & Macon County, NC & $\mathrm{B}$ & 1989 & SCR & $23.3 \pm 13.3$ \\
\hline NC87 & C. florida & Macon County, NC & $\mathrm{B}$ & 1989 & SCR & $95.0 \pm 2.9$ \\
\hline $\mathrm{NC} 009$ & C. florida & Macon County, NC & $\mathrm{B}$ & 2000 & NZ & $10.0 \pm 0$ \\
\hline GA77 & C. florida & White County, GA & $\mathrm{B}$ & 1989 & SCR & $10.0 \pm 5.0$ \\
\hline GA79 & C. florida & White County, GA & $\mathrm{F}$ & 1989 & SCR & $2.0 \pm 1.5$ \\
\hline GA80 & C. florida & Murray County, GA & B & 1989 & SCR & $18.0 \pm 9.3$ \\
\hline GA81 & C. florida & Murray County, GA & $\mathrm{F}$ & 1989 & SCR & $3.7 \pm 1.3$ \\
\hline
\end{tabular}

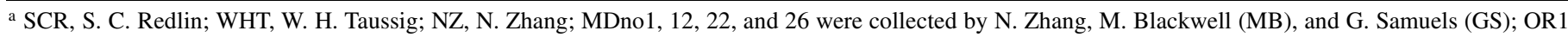
and OR2 were collected by G. Carroll (GC); and MDRR1 to MDRR10 were collected by R. Reddinger (RR).

b Virulence results at $23^{\circ} \mathrm{C}$, mean percent infected leaf area \pm standard error. 
AF429756 to AF429761, AF424787, and AF424788) were obtained for four eastern and two western isolates. The IGS of eastern isolates was approximately $600 \mathrm{bp}$ longer than that of western isolates, and there was a fixed 5-bp indel between the western and eastern isolates at positions 342 to 346 . From position 459 to 600 , the sequences were too variable between the western and eastern isolates to be aligned; however, variation was not detected with- in either the EAST or the WEST clusters. The $3^{\prime}$ end of the IGS region was invariant.

\section{DISCUSSION}

Population structure. One of our primary goals was to investigate the population structure of $D$. destructiva. A large number of

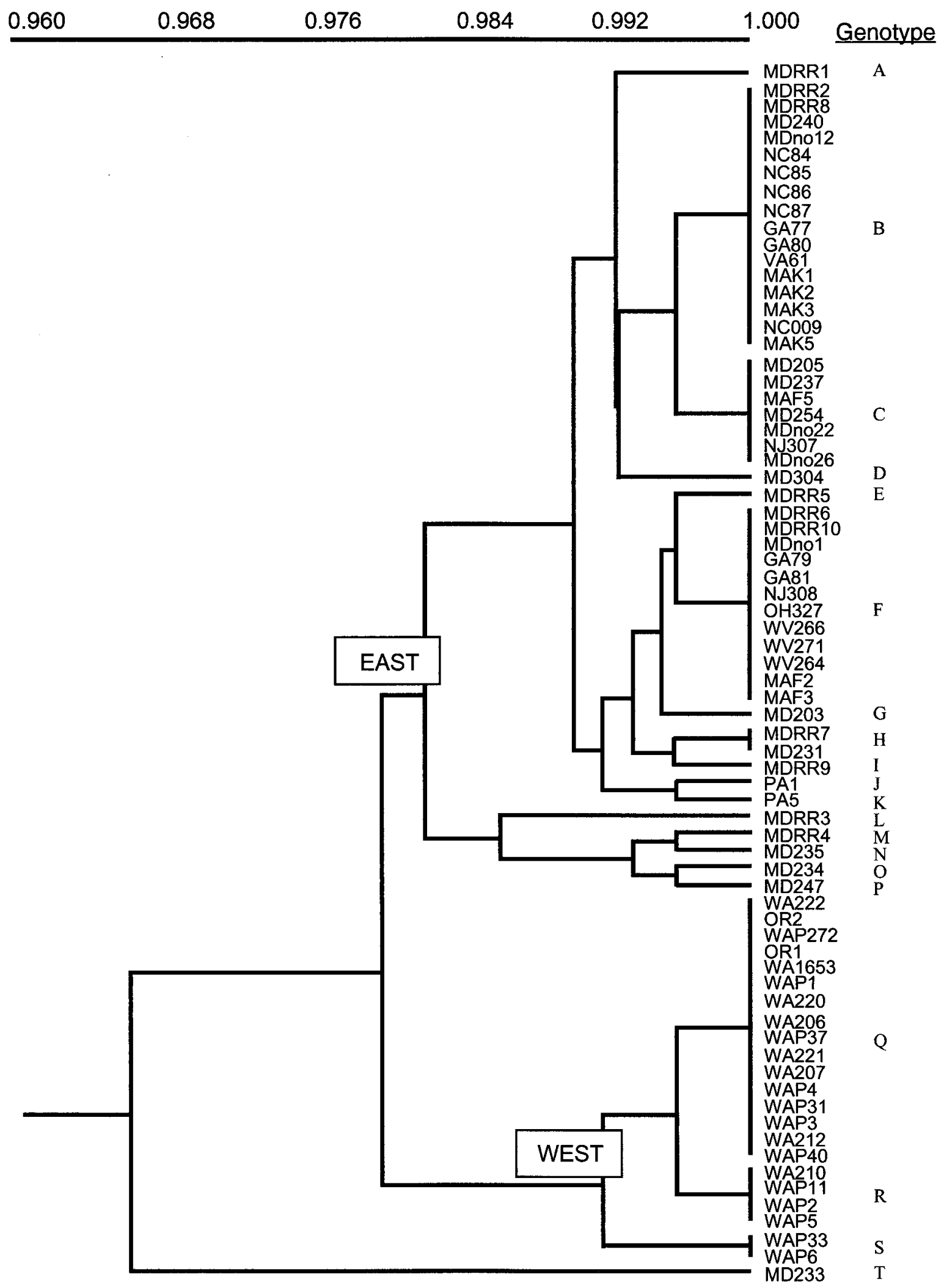

Fig. 2. Phenogram of 72 Discula destructiva isolates based on amplified fragment length polymorphism results using Nei and Li's genetic similarity method (22). The similarity coefficient is indicated above the phenogram. 
reports and papers have been published on the progression of the dogwood anthracnose epidemic since its first appearance in the 1970 s, but only a small number of of these were population studies. Trigiano et al. (37) used DAF markers to find that the $D$. destructiva isolates were highly homogeneous across different collection localities and host species. Caetano-Anollés et al. (6) used ASAP markers and reported a genetic difference between the western and eastern isolates collected a decade ago and even subpopulation structure in the east. However, they arbitrarily combined as many as eight fungal isolates in one experimental sample according to their geographical location, which may have resulted in bias in presumed geographical variation. Moreover, some additional analyses are impossible based on results of pooled samples. One experiment with unpooled material included only a limited number of isolates, and variation of the ITS sequences also was detected in a more recent study (7). They identified five distinct ITS sequences among $18 \mathrm{D}$. destructiva isolates, but neither host nor geographical locations were reflected in the groupings.

In our study, we included $72 \mathrm{D}$. destructiva isolates from a wide geographical range, 17 of which were collected during 1999 and 2000 and the others were collected about a decade ago. The AFLP markers identified 20 genotypes, but most of the isolates belonged to one of the five widespread clones. The western and eastern isolates were clearly separated, a finding that agrees with the results of Caetano-Anollés et al. (6). We also found that the western isolates had a remarkably lower genotypic diversity than eastern isolates (Table 2). These results could be caused by sampling bias; however, the relatively sample size insensitive diversity index, Fisher's $\alpha$, also indicated a significantly higher diversity in the eastern isolates (9.07) than in the western isolates (0.93) (12). In addition, the two Oregon collections from the year 2000 fell into one of the three genotypes found in Washington isolates collected a decade ago, indicating that the western population may have been less diverse. In the EAST cluster, most of the isolates also belonged to one of the three widespread clones. However, nine genotypes were found among 11 isolates collected in 1990 from an area of only approximately $10 \mathrm{~km}^{2}$ in CMNP, Maryland. Within the 11 collections made in the same area 9 years later, five genotypes were identified as new (Fig. 2). Moreover, a more recent study revealed that the eastern isolates contained a greater diversity of dsRNA than did the western isolates (32). These results all corroborate the finding that the eastern $D$. destructiva population is more genetically diverse than the western population.

Host plant diversity is an important consideration in pathogen genetic variability. There are more Cornus spp. in eastern North America than in the west (19). Although $D$. destructiva has not been reported from all species of Cornus, a search is needed to determine if it is present in other Cornus spp. In addition, the broader distribution of the known eastern host $C$. florida (from Maine to Mexico and Florida) than the western host species $C$. nuttallii suggests possible greater genetic diversity within the eastern host species. There is, however, no study to support this intuitive conclusion (J. Xiang, personal communication, 2001). Higher host genetic diversity would be expected to be correlated with the higher variability that was detected in the eastern $D$. destructiva isolates.

Dogwood anthracnose was first noticed in the east in the southeastern New York, southwestern Connecticut region, from which the disease spread subsequently both northward and southward. It has been hypothesized that the disease was introduced from the port of New York (9). We divided the eastern isolates into two groups, a central group from the area around New York City and the frontal group from regions radiating outward from New York. The more recent isolates (1999 to 2000) were excluded from this comparison. Although the central group was from a smaller area and had fewer isolates, its much higher genotypic diversity (0.94 versus 0.56) and many more genotypes (12 versus 3) compared with that of the frontal group support the New York area as the epidemic center, and indicates that a search for the origin of the pathogen abroad might be productive. Because kousa dogwood (C. kousa), which has been imported to the United States from Asia since 1875 , is usually more resistant to the disease than the native dogwoods $(27,33)$, Asia might be a productive region to begin to search for $D$. destructiva or its ancestors if the disease was, in fact, introduced.

Virulence. Although the decade-old group of isolates centered around New York City had higher genotypic diversity, there virulence was not significantly different from that of the frontal group. The western isolates were more virulent on average than the eastern ones, but this difference also was not significant (Table 2). The 1999 CMNP isolates were significantly more virulent than the 1990 isolates, with a $P$ value of 0.0007 . The length of time that the cultures were preserved might have influenced reduced culture viability or virulence of the pathogen, but one should not ignore the experimentally high infection rate of western isolates in culture since 1990 or before on the flowering dogwood leaves. In fact, this experimental evidence also signals the potential for spread of western fungal population members to the eastern native flowering dogwoods, causing a new wave of disease. Field tests would be very valuable to assess these results, and a better way to test virulence would be to use conidia to inoculate wounded intact leaves on healthy living dogwood trees. In our study, the high variation of virulence observed in some cases (Table 1) might be due to differences among the leaf disks, such as leaf age, location on the tree, position on the leaf, and the use of only three replicates.

Three more $t$ tests were done in order to determine if the isolates of widespread genotypes are more virulent than those of less common genotypes. In the eastern decade-old collection group, western decade-old collection group, and eastern new collection group, virulence of isolates from the widespread genotypes (those having more than four isolates of a single genotype) were compared with those of less common genotypes (those having only one to four isolates of a genotype). In all three of the groups, the widespread isolates had higher average virulence; however, the $P$ values were greater than $0.05(0.38,0.27$, and 0.14$)$, and therefore, widespread isolates could not be linked to high virulence or fitness with statistical support.

TABLE 2. Diversity and virulence comparison of Discula destructiva isolates of different locality, time, and genotypic group ${ }^{\mathrm{a}}$

\begin{tabular}{|c|c|c|c|c|}
\hline Group & Number of isolates & Genotypic diversity & Fisher's $\alpha$ & Virulence (\% infection) $)^{\mathrm{b}}$ \\
\hline WEST cluster & 22 & $0.45^{*}$ & $0.93 *$ & 37.9 \\
\hline EAST cluster & 49 & $0.82 *$ & $9.07 *$ & 36.9 \\
\hline Catoctin Mountain Park 1990 (Maryland) & 9 & 0.97 & 23.14 & $23.5^{*}$ \\
\hline Catoctin Mountain Park 1999 (Maryland) & 11 & 0.93 & 10.88 & $60.0^{*}$ \\
\hline \multicolumn{5}{|l|}{ Eastern central 1989 to 1990} \\
\hline Maryland, New Jersey, Pennsylvania & 15 & $0.94 *$ & $27.86 *$ & 34.8 \\
\hline \multicolumn{5}{|l|}{ Eastern frontal 1989 to 1990} \\
\hline Georgia, Massachusetts, North Carolina, Virginia, West Virginia & 20 & $0.56^{*}$ & $0.95 *$ & 26.4 \\
\hline
\end{tabular}

a $*$ Indicates significant difference at $P<0.05$ according to the $t$ test.

$\mathrm{b}$ The percentage of leaf area that contained conidiomata of $D$. destructiva after 3 weeks incubation at $23^{\circ} \mathrm{C}$. 
Our cultural studies indicated that temperature is critical to virulence. $D$. destructiva did not affect dogwood leaves at $28^{\circ} \mathrm{C}$ or above in the laboratory, a factor that helps to explain its restricted geographical distribution in nature. The fungus occurs at high elevations or northern coastal areas, and its southern-most distribution is northern California in the west and northern Alabama in the east $(11,17)$.

Many different fungal plant pathogens contain dsRNAs in their cytoplasm, some of which are related to reduced or enhanced virulence of the fungal hosts (23). Lateral transmission of dsRNAs requires somatic anastomosis (14), and therefore, vegetative compatibility is important for the spread of dsRNAs between fungal individuals. The apparent vegetative compatibility among all 72 $D$. destructiva isolates inferred that the dsRNA factors may be transferred across all the isolates. Caetano-Anollés et al. (7) also found vegetative compatibility among their $D$. destructiva isolates. The effect of dsRNAs on virulence of $D$. destructiva has not been determined, but the difficulty that was encountered in spreading dsRNAs in the chestnut blight fungal population (1) probably would not be observed in D. destructiva.

Episodic selection and speciation. Among both eastern and western isolates, a few clones were widespread, and the genetic variability of this apparently asexual fungus was remarkably low compared with that of many other asexual fungal species from both AFLP and sequencing results $(2,7,16,35,39)$. This led us to suggest that $D$. destructiva is still under intense selection pressure and that episodic selection is still in effect. Future studies on the population dynamics will be needed to determine which direction D. destructiva is taking, to a less virulent, more heterogeneous population, or to retain its high virulence and clonal population structure.

We cannot provide a definite reason for the observed variation either between or among isolates of the eastern and western groups. The western and eastern isolates were easily distinguished from each other by AFLP and sequence analysis, and our data suggest that the two large independent clusters might be the result of separate introductions. This explanation also has been suggested by other researchers $(6,41)$. In our opinion, the degree of diversity between the eastern and western clusters does not merit recognition of two distinct species, although the detected polymorphisms in IGS, EF1- $\alpha$, and $\beta$-tubulin gene sequences occurred between, not within the two large clusters. The variation within each of the groups also could be due to past multiple introductions. At this time, we cannot, however, answer the question of how much genetic divergence might have occurred over the intervening 20 years since the recognition of the disease in the presumed absence of sexual reproduction. Several mechanisms besides multiple introductions into each geographical region might, however, help to explain the levels, although low, of variation. These include drift, mutation, selection, and undetected genetic recombination. More evidence is needed before firmer conclusions can be made, but our work should serve as a baseline study for monitoring the fungus in the future.

\section{ACKNOWLEDGMENTS}

This study was supported, in part, by The Louis Stokes Louisiana Alliance for Minority Participation to L. Barber, a Louisiana State University graduate school special achievement award, and a grant to the Biological Computation and Visualization Center at Louisiana State University from the Louisiana Board of Regents (BOR HEF (2000-05)-01). We thank S.-O. Suh for providing helpful advice on analysis and molecular techniques throughout this study; N. Crochet for technical assistance in sequencing; L. Barber for helping perform the virulence tests; S. Redlin and R. Schultheiss for providing over $70 \mathrm{D}$. destructiva cultures, of which 55 were included in this study; S. Redlin for providing advice on virulence tests; $\mathrm{S}$. Anagnostakis for helpful discussions at the beginning of the study and for extracting some of the DNA samples; G. Samuels, G. Carroll, and R. Reddinger for helping us collect the Mary- land and Oregon samples; D. Geiser, J. Xiang, J. Denslow, M. Hellberg, and S. DeWalt for advice on population biology; and W. Taussig and A. Rossman for additional isolates.

\section{LITERATURE CITED}

1. Anagnostakis, S. L. 1982. Biological control of chestnut blight. Science 215:466-471.

2. Boucias, D., Stokes, C., Suazo, A., and Funderburk, J. 2000. AFLP analysis of the entomopathogen Nomuraea rileyi. Mycologia 92:638648.

3. Brasier, C. M. 1987. The dynamics of fungal speciation. Pages 231-260 in: Evolutionary Biology of the Fungi. A. D. M. Rayner, C. M. Brasier, and D. Moore, eds. Cambridge University Press, England.

4. Brasier, C. M. 1995. Episodic selection as a force in fungal microevolution, with special reference to clonal speciation and hybrid introgression. Can. J. Bot. 73(suppl. 1):S1213-S1221.

5. Byther, R. S., and Davidson, R. M., Jr. 1979. Dogwood anthracnose. Ornamentals Northwest Newsl. 3:20-21.

6. Caetano-Anollés, G., Trigiano, R. N., and Windham, M. T. 1996. Sequence signatures from DNA amplification fingerprints reveal fine population structure of the dogwood pathogen Discula destructiva. FEMS Microbiol. Lett. 145:377-383.

7. Caetano-Anollés, G., Trigiano, R. N., and Windham, M. T. 2001. Patterns of evolution in Discula fungi and the origin of dogwood anthracnose in North America, studied using arbitrarily amplified and ribosomal DNA. Curr. Genet. 39:346-354

8. Carbone, I., and Kohn, L. M. 1999. A method for designing primer sets for speciation studies in filamentous ascomycetes. Mycologia 91:553556.

9. Daughtrey, M. L. 1993. Dogwood anthracnose disease: Native fungus or exotic invader? Pages 23-33 in: Biological Pollution: The Control and Impact of Invasive Exotic Species. B. N. McKnight, ed. Indiana Acad. Sci. Indianapolis.

10. Daughtrey, M. L., and Hibben, C. R. 1994. Dogwood anthracnose: A new disease threatens two native Cornus species. Annu. Rev. Phytopathol. 32:61-73.

11. Daughtrey, M. L., Hibben, C. R., Britton, K. O., Windham, M. T., and Redlin, S. C. 1996. Dogwood anthracnose-Understanding a disease new to North America. Plant Dis. 80:349-358.

12. DeWalt, S. J., Schnitzer, S. A., and Denslow, J. S. 2000. Density and diversity of lianas along a chronosequence in a central Panamanian lowland forest. J. Trop. Ecol. 16:1-19.

13. Farr, D. F., Bills, G. F., Chamuris, G. P., and Rossman, A. Y. 1989. Fungi on Plants and Plant Products in the United States. The American Phytopathological Society, St. Paul, MN.

14. Ghabrial, S. 1998. Origin, adaptation and evolutionary pathways of fungal viruses. Virus Genes 16:119-131.

15. Glass, N. L., and Donaldson, G. C. 1995. Development of primer sets designed for use with the PCR to amplify conserved genes from filamentous ascomycetes. Appl. Environ. Microbiol. 61:1323-1330.

16. González, M., Rodríguez, R., Zavala, M. E., Jacobo, J. L., Hernández, F., Acosta, J., Martínez, O., and Simpson, J. 1998. Characterization of Mexican isolates of Colletotrichum lindemuthianum by using differential cultivars and molecular markers. Phytopathology 88:292-299.

17. Hagan, A. K., and Mullen, J. M. 1999. Occurrence of diseases in native stands of flowering dogwood in north Alabama. Ala. Agric. Exp. Stn. Bull. 639:1-15.

18. Hibben, C. R., and Daughtrey, M. L. 1988. Dogwood anthracnose in northeastern United States. Plant Dis. 72:199-203.

19. Little, E. L., Jr. 1971. Atlas of United States trees. Vol. 1. Conifers and Important Hardwoods. U.S. Dep. Agric. Misc. Publ. 1146.

20. Magurran, A. E. 1988. Ecological Diversity and Its Measurement. Princeton University Press, Princeton, NJ.

21. Nei, M. 1987. Molecular Evolutionary Genetics. Columbia University Press, New York.

22. Nei, M., and Li., W.-H. 1979. Mathematical model for studying genetic variation in terms of restriction endonucleases. Proc. Natl. Acad. Sci. USA 76:5269-5273.

23. Nuss, D. L., and Koltin, Y. 1990. Significance of dsRNA genetic elements in plant pathogenic fungi. Annu. Rev. Phytopathol. 28:37-58.

24. Pirone, P. P. 1980. Parasitic fungus affects region's dogwood. New York Times, NY.

25. Prochazka, M., Walder, K., and Xia, J. 2001. AFLP fingerprinting of the human genome. Hum. Genet. 108:59-65.

26. Rademaker, J. L. W., Hoste, B., Louws, F. J., Kersters, K., Swings, J., Vauterin, L., Vauterin, P., and de Bruijn, F. J. 2000. Comparison of AFLP and rep-PCR genomic fingerprinting with DNA-DNA homology studies: Xanthomonas as a model system. Int. J. Syst. Evol. Microbiol. 50: 
665-677.

27. Ranney, T. G., Grand, L. F., and Knighten, J. L. 1995. Susceptibility of cultivars and hybrids of kousa dogwood to dogwood anthracnose and powdery mildew. J. Arboric. 21:11-16.

28. Redlin, S. C. 1991. Discula destructiva sp. nov., cause of dogwood anthracnose. Mycologia 83:633-642.

29. Rehner, S. A., and Samuels, G. J. 1995. Molecular systematics of the Hypocreales: A teleomorph gene phylogeny and the status of their anamorphs. Can. J. Bot. 73(Suppl. 1):S816-S823.

30. Reineke, A., Karlovsky, P., and Zebitz, C. P. W. 1999. Amplified fragment length polymorphism analysis of different geographic populations of the gypsy moth, Lymantria dispar (Lepidoptera: Lymantriidae). Bull. Entomol. Res. 89:79-88.

31. Rizwana, R., and Powell, W. A. 1992. Ultraviolet light-induced instability of vegetative compatibility groups of Cryphonectria parasitica. Phytopathology 82:1206-1211.

32. Rong, R., Rao, S., Scott, S. W., and Tainter, F. H. 2001. Common multiple dsRNAs are present in populations of the fungus Discula destructiva originating from widely separated geographic locations. Curr. Microbiol. 42:144-148.

33. Santamour, F. S., Jr., McArdle, A. J., and Strider, P. V. 1989. Susceptibility of flowering dogwood of various provenances to dogwood anthracnose. Plant Dis. 73:590-591.

34. Sharma, S. K., Knox, M. R., and Ellis, T. H. N. 1996. AFLP analysis of the diversity and phylogeny of Lens and its comparison with RAPD analysis. Theor. Appl. Genet. 93:751-758.

35. Skovgaard, K., Nirenberg, H. I., O’Donnell, K., and Rosendahl, S. 2001. Evolution of Fusarium oxysporum f. sp. vasinfectum races inferred from multigene genealogies. Phytopathology 91:1231-1237.

36. Tredway, L. P., White, J. F., Gaut, B. S., Reddy, P. V., Richardson, M. D., and Clarke, B. B. 1999. Phylogenetic relationships within and between Epichlö̈ and Neotyphodium endophytes as estimated by AFLP markers and rDNA sequences. Mycol. Res. 103:1593-1603.

37. Trigiano, R. N., Caetano-Anollés, G., Bassam, B. J., and Windham, M. T. 1995. DNA amplification fingerprinting provides evidence that Discula destructiva, the cause of dogwood anthracnose in North America, is an introduced pathogen. Mycologia 87:490-500.

38. Van Der Hulst, R. G. M., Mes, T. H. M., Den Nijs, J. C. M., and Bachmann, K. 2000. Amplified fragment length polymorphism (AFLP) markers reveal that population structure of triploid dandelions (Taraxacum officinale) exhibits both clonality and recombination. Mol. Ecol. 9:1-8.

39. Vandemark, G., Martínez, O., Pecina, V., and Alvarado, M. D. 2000. Assessment of genetic relationships among isolates of Macrophomina phaseolina using a simplified AFLP technique and two different methods of analysis. Mycologia 92:656-664.

40. White, T. J., Bruns, T. D., Lee, S. B., and Taylor, J. W. 1990. Analysis of phylogenetic relationships by amplification and direct sequencing of ribosomal DNA genes. Pages 315-322 in: PCR Protocols: A Guide to Methods and Applications. M. A. Innis, D. H. Gelfand, J. J. Sninsky, and T. J. White, eds. Academic Press, New York.

41. Yao, J. M., McElreath, S. D., and Tainter, F. H. 1997. Double-stranded RNA in isolates of Discula destructiva from the Pacific northwestern United States and British Columbia, Canada. Curr. Microbiol. 34:67-69.

42. Yee, E., Kidwell, K. K., Sills, G. R., and Lumpkin, T. A. 1999. Diversity among selected Vigna angularis (Azuki) accessions on the basis of RAPD and AFLP markers. Crop Sci. 39:268-275.

43. Zhang, N., and Blackwell, M. 2001. Molecular phylogeny of dogwood anthracnose fungus (Discula destructiva) and the Diaporthales. Mycologia 93:355-365. 